\title{
Inhalt
}

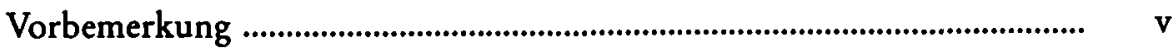

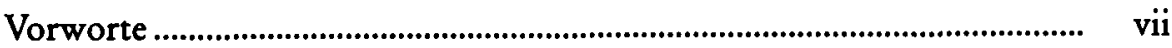

STEFAN ZrMmer

Germani und die Benennungsmotive für Völkernamen in der Antike.... 1

SIEGMAR VON SCHNURBEIN

Germanien in römischer Sicht. Germania Magna und die römischen

Provinzbezeichnungen

Dieter Mertens

Die Instrumentalisierung der „Germania“ des Tacitus durch die deutschen Humanisten

Uwe Puschner

Germanenideologie und völkische Weltanschauung

JOACHIM EHLERS

Erfundene Traditionen? Zum Verhältnis von Nationsbildung und

Ethnogenese im deutschen und französischen Mittelalter

Walter Pohl.

Der Germanenbegriff vom 3. bis zum 8. Jahrhundert - Identifikationen und Abgrenzungen

Dieter Geuenich

Karl der Große, Ludwig „der Deutsche“ und die Entstehung eines "deutschen" Gemeinschaftsbewußtseins

Wolfgang Haubrichs

Theodiscus, Deutsch und Germanisch - drei Ethnonyme, drei

Forschungsbegriffe. Zur Frage der Instrumentalisierung und

Wertbesetzung deutscher Sprach- und Volksbezeichnungen 
HANS-WERNER GOETZ

Die „Deutschen Stämme" als Forschungsproblem

JöRG JARNưT

Die Entstehung des mittelalterlichen deutschen Reiches als

Forschungsproblem

ROSEMARIE MÜLLER

Reaktionen auf die Gleichung "germanisch-deutsch“ im östlichen

Mitteleuropa

Sebastian Brather

„Frühdeutsch“. Ein Begriff der Archäologie des Mittelalters?

Hans Frede Nielsen

On the Terms for Germanic Employed by Scandinavian Scholars

in the 19th and 20th Centuries

Thomas A. SHIPPEY

Germanen, Deutsche und Teutonen in der englischsprachigen

Geistesgeschichte

Patrick J. Geary

"Teutonische" Rassenideologie im Amerika des 19. Jahrhunderts

Heiko Steuer

Das „völkisch" Germanische in der deutschen Ur- und Frühgeschichtsforschung. Zeitgeist und Kontinuitäten

Gerhard Schmitz

Zur Entstehungsgeschichte der Monumenta Germaniae Historica 503

\section{Dietrich Hakelberg}

Adliges Herkommen und bürgerliche Nationalgeschichte.

Hans von Aufseß und die Vorgeschichte des Germanischen Nationalmuseums in Nürnberg

FRIEDRICH-WILHELM VON HASE

Zur Frühgeschichte des Römisch-Germanischen Zentralmuseums. Forschungsinstitut für Vor- und Frühgeschichte in Mainz und der Römisch-Germanischen Kommission des Deutschen Archäologischen Instituts in Frankfurt am Main 
HEINRICH BECK

"Germanische Altertumskunde“ -

Annäherung an eine schwierige Disziplin

Klaus Düwel

Zur Benennung der Universitäts-Institute: „Germanistisches Seminar“ oder „Seminar für Deutsche Sprache und Literatur“

Nachwort

Register . 
